\title{
Knowledge and Awareness on Cementation Protocols for Fixed Partial Dentures Among Dental Students
}

\author{
Vaishali. S', Subhabrata Maiti ${ }^{*}$ and Jessy $\mathrm{P}^{3}$ \\ ${ }^{1}$ Saveetha Dental College and Hospitals Saveetha Institute of Medical \\ and Technical Sciences (SIMATS) Saveetha University, Chennai, India \\ ${ }^{2}$ Assistant professor Department of Prosthodontics Saveetha Dental College and Hospitals Saveetha \\ Institute of Medical and Technical Sciences (SIMATS) Saveetha University, Chennai, India \\ ${ }^{3}$ Assistant professor Department of Pedodontics Saveetha Dental College and Hospitals Saveetha \\ Institute of Medical and Technical Sciences (SIMATS) Saveetha University, Chennai, India
}

\begin{abstract}
Continuous development of technology in dental medicine and the high esthetic demands of the patients determined an increased awareness regarding the success of treatment among the clinical practice of dental students. The longevity of prosthesis depends on the type of luting cement, isolation techniques and the protocols used with tooth preparation. So it is important to educate students regarding this to achieve successful bonding of FPD. The aim of this study was to evaluate the knowledge and awareness of cementation protocols for Fixed Partial Dentures (FPDs) among undergraduate and postgraduate dental students in achieving success of Fixed dental prosthesis. It is a university setting study. Total of 150 students both undergraduate and postgraduates who are practicing in dental clinics in saveetha dental college were included in this study. A questionnaire containing 15 questions focused on the perceptions and experiences on protocols followed by dental students for cementation of prosthesis were given to them.The data obtained was entered in excel and imported to SPSS. Chi square association was done to compare the responses between undergraduates and postgraduates and were represented in the form of bar graphs. Out of 150 students, $70 \%$ were undergraduate and $30 \%$ were postgraduate students. $19.33 \%$ of the postgraduates were aware about all of the protocols followed during cementation, whereas majority of the undergraduates chose isolation as the protocols to be followed $13.33 \%$ of the postgraduates and $49.33 \%$ of the undergraduates, both were equally aware that inadequate isolation majorly as led to the failure of FPD post cementation, which was statistically significant ( $p<0.05) .20 \%$ of the postgraduates were aware about all the steps to be followed during re-cementation of FPD, whereas majority of the undergraduates chose better isolation to be followed, which shows that post graduates were more aware about re-cementation protocols than undergraduates and was statistically significant ( $<<0.05)$. This survey shows that both undergraduate and postgraduate dental students have fairly good knowledge about the cementation protocols for FPD.Through increased awareness of dental students expectations and experiences, restorations can be planned, made and placed in harmony with the hard and soft oral tissues, and in harmony with the patient's expectation as well
\end{abstract}

KEY WORDS: CEMENTATION, FIXED PARTIAL DENTURES, ISOLATION, POSTGRADUATES, UNDERGRADUATES.

\section{ARTICLE INFORMATION}

${ }^{*}$ Corresponding Author: drsubhoprostho@gmail.com

Received 28th June 2020 Accepted after revision 7th August 2020

Print ISSN: 0974-6455 Online ISSN: 2321-4007 CODEN: BBRCBA

Thomson Reuters ISI Web of Science Clarivate Analytics USA and Crossref Indexed Journal

\section{Clarivate
Analytics}

NAAS Journal Score 2020 (4.31) SJIF: 2020 (7.728)

A Society of Science and Nature Publication,

Bhopal India 2020. All rights reserved.

Online Contents Available at: http//www.bbrc.in/

Doi: http://dx.doi.org/10.21786/bbrc/13.7/36

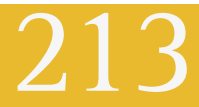




\section{INTRODUCTION}

Edentulism and dental disease have a profound effect on the quality of life of patients. Tooth loss is a common finding among individuals (Fiske et al., 1998) . Despite the ongoing progress in oral health services offered world wide, had caused a reduced number of partially dentate patients, demanding care in fact as it really widened (Loera, no date). Loss of tooth or tooth form often occurs due to caries, periodontal pathology or trauma (Rosenstiel and Land, 2001).

Fixed prosthetic replacement and restoration of teeth restores form, function and aesthetic of the damaged or lost dentition. Fixed prosthodontics treatment modality provides exceptional satisfaction for both patients and the dental practitioner (Kannan et al., 2018). It can transform an displeasing, unhealthy dentition with poor function into a more comfortable, healthy occlusion capable of years of further oral activity while greatly improving aesthetics. The quality of construction of fixed prostheses directly affects its long-term survival (Prath, Ashwatha Prath and Jain, 2017). It is essential that the dental practitioner follows all the fundamental clinical guidelines for longevity of the treatment.

Continuous development of technology in dental medicine and the high esthetic demands of the patients determined an increased awareness regarding the success of treatment among the clinical practice of dental students (Rosenstiel, Land and Crispin, 1998). The longevity of prosthesis depends on the type of luting cement, isolation techniques and the protocols used with tooth preparation (Hill, 2007). The clinician's understanding of various cements, their advantages and disadvantages is of utmost importance. In recent years, isolation techniques, protocol measures, luting agents cements have been introduced claiming clinically better performance than existing materials due to improved characteristics (Macorra, de la Macorra and Pradíes, 2002).

The foremost goal of any clinician is providing the patient with a restoration which preserves the longevity and pulpal vitality of natural abutments of fixed partial dentures and regaining the lost function (Chen et al., 2006). A luting agent is defined as the application of a dental cement connecting the underlying prepared tooth structure to a fixed dental prosthesis. A luting agent's primary and most vital function is to fill the voids present at the restoration-tooth interface so as to prevent any marginal leakage which may lead to secondary caries and mechanically interlock the prosthesis in place to prevent its dislodgement during masticatory activities (Diaz-Arnold, Vargas and Haselton, 1999). Depending on the expected longevity of the dental cement, a luting agent may be classified into definitive (long term) or provisional (short term) restoration. In recent years, many luting agents and dental cements have been introduced with better clinical performance than existing materials due to improved characteristics.
Post cementation sensitivity is one of the most significant complications in fixed Prosthodontics, especially when the prosthesis is cemented on teeth with vital pulps (Hill and Rubel, 2009). However, the incidence of this post cementation complication is underestimated by most clinicians. The selection of permanent luting cement for fixed partial dentures is critical as it has an important role to play in controlling the post cementation sensitivity and success of the final prosthesis.

Previously our department has published extensive research on various aspects of prosthetic dentistry ('Evaluation of Corrosive Behavior of Four Nickelchromium Alloys in Artificial Saliva by Cyclic Polarization Test:An in vitro Study', 2017; Ganapathy, Kannan and Venugopalan, 2017; Jain, 2017a, 2017b; Ranganathan, Ganapathy and Jain, 2017; Ariga et al., 2018; Gupta, Ariga and Deogade, 2018; Anbu et al., 2019; Ashok and Ganapathy, 2019; Duraisamy et al., 2019; Varghese, Ramesh and Veeraiyan, 2019), this vast research experience has inspired us to research about knowledge and awareness of cementation protocols for Fixed Partial Dentures (FPDs) among undergraduate and postgraduate dental students in achieving success of Fixed dental prosthesis.

Figure 1: Questionnaire regarding cementation protocol for Fixed Partial Denture

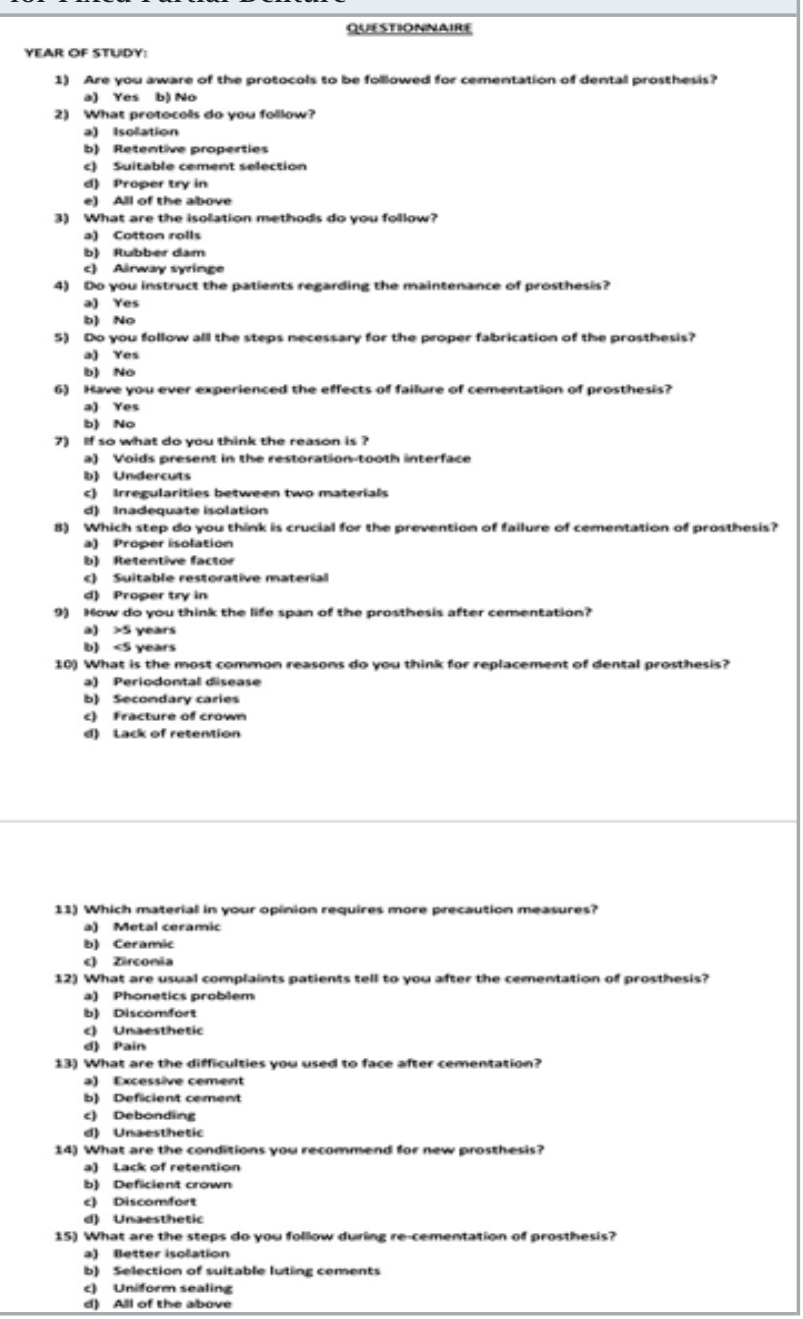




\section{MATERIAL AND METHODS}

Study setting: It is a university setting study, conducted in Saveetha Dental College from November 2019 to January 2020. The pros of the study are flexibility, low cost. The cons of the study are that it is limited to a certain population. Total of 150 students who were pursuing their undergraduate and postgraduate studies in Saveetha dental college were randomly selected. Approval was obtained from the Institutional Ethical Committee (IEC), Saveetha Dental College. Two examiners were included in the study.

Sampling: Simple random sampling was done to minimise sampling bias. It was generalised to South Indian population.

Figure 2: Bar graph shows distribution of level of study of the study population. $\mathrm{X}$ axis shows the level of study and $\mathrm{Y}$ axis shows the percentage of students in each category. Out of 150 students, $70 \%$ were undergraduate and $30 \%$ were postgraduate students.

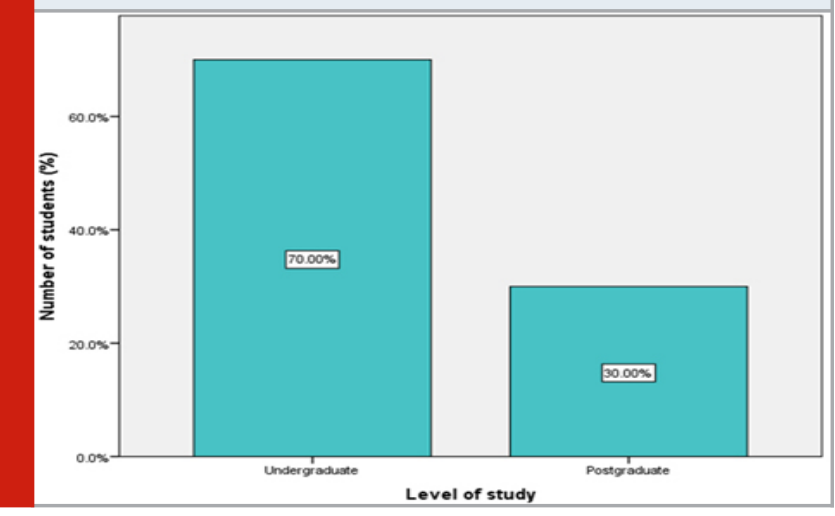

Data collection: Questionnaire based study. Questionnaires [Figure 1] consisting of fifteen questions focused on the perceptions and experiences on protocols followed by dental students for cementation of prosthesis were distributed through Survey planet link and were asked to fill by both the undergraduate and postgraduate students.

Analysis: Data was entered in excel in a methodical manner and was imported to SPSS software 2.0. Descriptive statistics were used to evaluate the distribution of undergraduate and postgraduate students. Chi square association was done to compare the responses between undergraduates and postgraduates and were represented in the form of bar graphs.

\section{RESULTS AND DISCUSSION}

In relation to the distribution of level of study of the study population, it was found that out of 150 students, $70 \%$ were undergraduate and $30 \%$ were postgraduate students [Figure 2]. In relation to association between protocols followed and level of study, it was seen that $19.33 \%$ of the postgraduates were aware about all of the protocols followed during cementation, whereas majority of the undergraduates chose isolation as the protocols to be followed, which shows that post graduates were aware mostly when compared to undergraduates regarding protocols to be followed during cementation, and was statistically significant .(Pearson Chi square $=36.588$, $p$ value $=0.001(<0.05)$, hence statistically significant $)$ [Figure 3 and Table 1] .

Figure 3: Bar graph shows association between protocols followed and level of study. $\mathrm{X}$ axis shows protocols followed during cementation of FPD and Y axis shows the percentage of students in both undergraduate and postgraduate categories.(Pearson Chi square $=36.588$, $\mathrm{p}$ value $=0.001 \quad(<0.05)$, hence statistically significant $)$ $19.33 \%$ of the postgraduates were aware about all of the protocols followed during cementation, whereas majority of the undergraduates were not aware of all the protocols followed and was statistically significant.

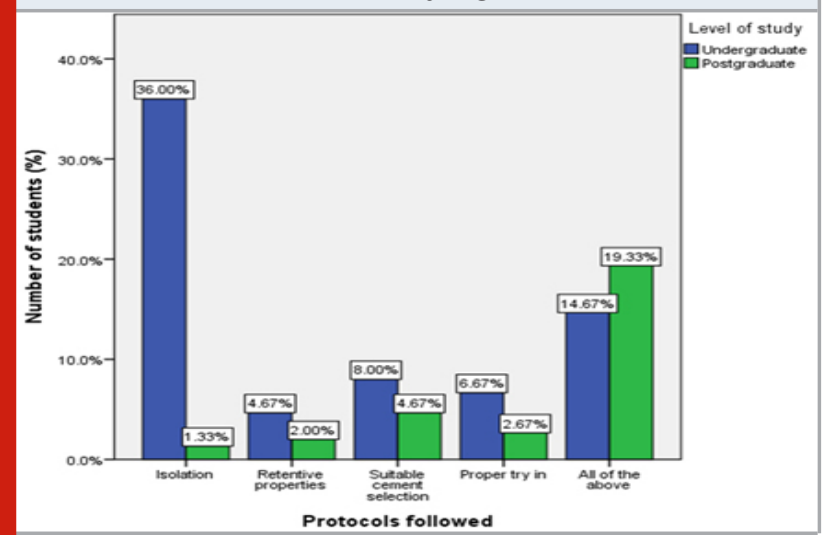

Figure 4: Bar graph shows association between isolation methods followed and level of study. $\mathrm{X}$ axis shows isolation methods followed during cementation of FPD and Y axis shows the percentage of students in both undergraduate and postgraduate categories.(Pearson Chi square $=7.465$ , p value $=0.024(<0.05)$, hence statistically significant $)$ $18 \%$ of the postgraduates and $56 \%$ of the undergraduates were equally aware that cotton rolls were majorly used as an isolation method followed during cementation, which was statistically significant.

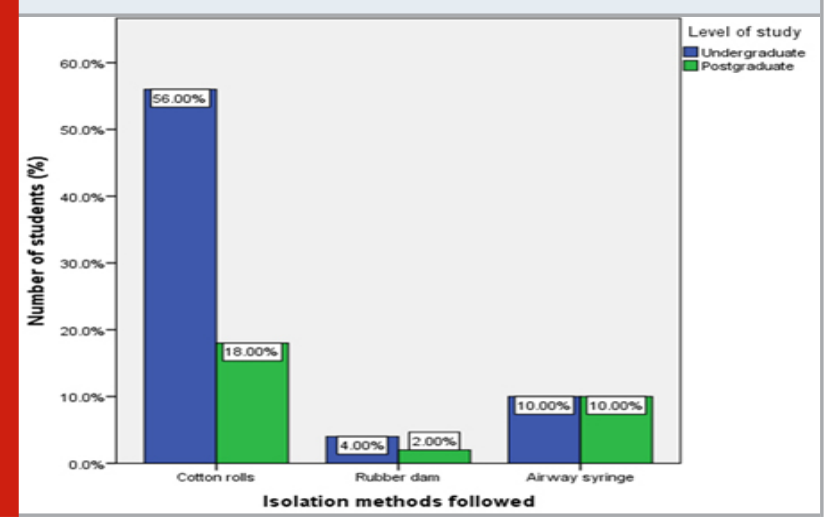


In relation to association between isolation methods followed and level of study, it was seen that $18 \%$ of the postgraduates and 56\% of the undergraduates were equally aware that cotton rolls were majorly used as an isolation method followed during cementation, which was statistically significant.(Pearson Chi square $=7.465$ , $p$ value $=0.024 \quad(<0.05)$, hence statistically significant $)$ [Figure 4 and Table 1]. In relation to association between reason for replacement of FPD and level of study it was seen thatv $10.67 \%$ of the postgraduates and $40 \%$ of the undergraduates, both were equally aware that fracture of crown majorly as led to the replacement of FPD, which was not statistically significant. (Pearson Chi square $=6.473, \mathrm{p}$ value $=0.91(>0.05)$, hence not statistically significant)[ Figure 5 and Table 1].

Figure 5: Bar graph shows association between reason for replacement of FPD and level of study. $\mathrm{X}$ axis shows for replacement of FPD and Y axis shows the percentage of students in both undergraduate and postgraduate categories. (Pearson Chi square $=6.473, p$ value $=0.91(>0.05)$, hence not statistically significant) $10.67 \%$ of the postgraduates and $40 \%$ of the undergraduates, both were equally aware that fracture of crown majorly as led to the replacement of FPD, which was not statistically significant.

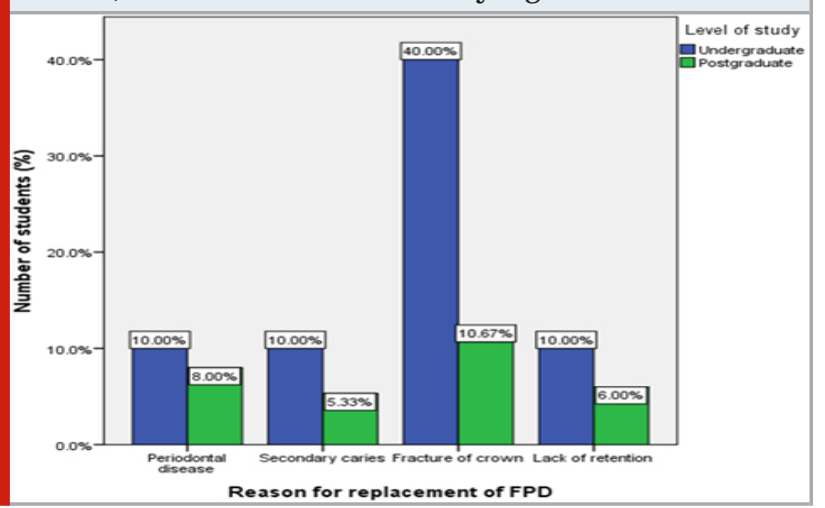

In relation to association between reason for failure of FPD and level of study, it was seen that $13.33 \%$ of the postgraduates and $49.33 \%$ of the undergraduates ,both were equally aware that inadequate isolation majorly as led to the failure of FPD post cementation, which was statistically significant. (Pearson Chi square $=11.307$, $p$ value $=0.010(<0.05)$, hence statistically significant $)$ [Figure 6 and Table 1]. In relation to association between steps followed during re-cementation of FPD and level of study, it was seen that $20 \%$ of the postgraduates were aware about all the steps to be followed during re-cementation of FPD, whereas majority of the undergraduates chose better isolation to be followed, which shows that post graduates were more aware about re-cementation protocols than undergraduates and was statistically significant. (Pearson Chi square $=20.015$, $p$ value $=0.001(<0.05)$, hence statistically significant $)$ [ Figure 7 and Table 1].

Dentistry is an art and science that should go hand in hand for a successful dental treatment. The clinical success of a dental restoration is determined by its resistance to fracture, marginal fit, esthetic outcome, and survival (Goodacre et al., 2003). A reliable marginal seal is among the factors that are vital to the clinical success of a dental restoration. This requires proper cementation protocols to be followed which results in ultimate prosthodontic success (Tan et al., 2004). This study discusses the knowledge and awareness of cementation protocols among both undergraduate and postgraduate dental students. Postoperative sensitivity after cementation of fixed prosthesis is a common complaint especially in cases where the abutments have vital pulp (Rosenstiel and Rashid, 2003)

Figure 6: Bar graph shows association between reason for failure of FPD and level of study. $\mathrm{X}$ axis shows reason for failure of FPD and $Y$ axis shows the percentage of students in both undergraduate and postgraduate categories. (Pearson Chi square $=11.307, \mathrm{p}$ value $=0.010$ $(<0.05)$, hence statistically significant) $13.33 \%$ of the postgraduates and $49.33 \%$ of the undergraduates ,both were equally aware that inadequate isolation majorly as led to the failure of FPD post cementation, which was statistically significant.

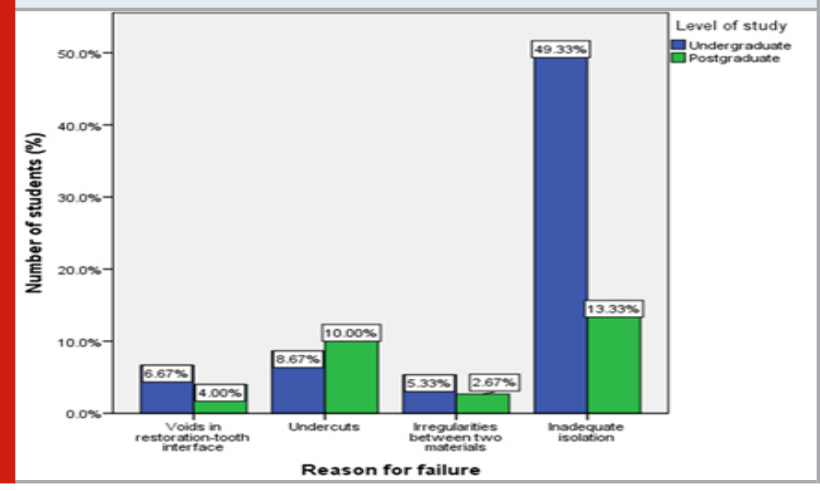

Figure 7: Bar graph shows association between steps followed during re-cementation of FPD and level of study. $\mathrm{X}$ axis shows steps followed during re-cementation of FPD and $Y$ axis shows the percentage of students in both undergraduate and postgraduate categories.(Pearson Chi square $=20.015$, $\mathrm{p}$ value $=0.001(<0.05)$, hence statistically significant) $20 \%$ of the postgraduates were aware about all the steps to be followed during re-cementation of FPD, whereas majority of the undergraduates chose better isolation to be followed, which shows that post graduates were more aware about re-cementation protocols than undergraduates and was statistically significant.

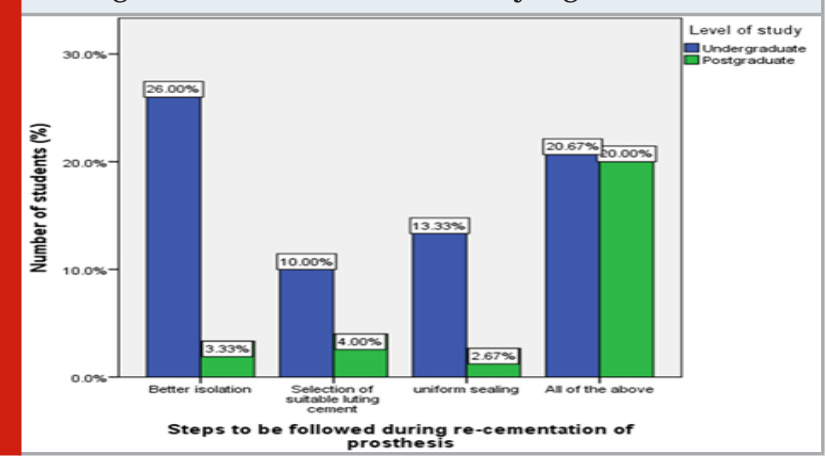


In relation to the protocols followed during cementation of Fixed partial dentures, post graduates were aware of all the protocols like isolation, retentive properties, suitable luting cement, proper try in etc, whereas undergraduates were not aware of all the protocols. This was in line with the study by Keerthana et al (Keerthna, Dhanraj and Jain, 2018), where majority of the dental students were aware about the protocols followed during cementation of fixed partial dentures. The selection of the luting agent for fixed dental prosthesis with vital abutments is considered critical as it has an important role to play in controlling post cementation sensitivity and success of the final prosthesis.So it is important that students should be aware of all the factors necessary for proper cementation of Fixed dental prosthesis.

Table 1 . Shows questions of the survey, options, responses from undergraduates and postgraduates along with cumulative response, chi square value and $\mathrm{p}$ value have been reported.

\begin{tabular}{|c|c|c|c|c|c|c|}
\hline Questions & Responses & $\begin{array}{l}\text { Response by } \\
\text { undergraduates } \\
(\%)\end{array}$ & $\begin{array}{l}\text { Response by } \\
\text { postgraduates } \\
(\%)\end{array}$ & $\begin{array}{l}\text { Cumulative } \\
\text { Response } \\
\text { (\%) }\end{array}$ & $\begin{array}{l}\text { Chi } \\
\text { square } \\
\text { test }\end{array}$ & $\begin{array}{c}\mathrm{p} \\
\text { value }\end{array}$ \\
\hline \multirow{2}{*}{$\begin{array}{l}\text { Are you aware of the } \\
\text { protocols to be followed } \\
\text { for cementation of FPD? }\end{array}$} & Yes & 52 & 26.67 & 78.67 & & \\
\hline & No & 18 & 1.33 & 19.33 & 9.138 & $0.003^{*}$ \\
\hline \multirow[t]{3}{*}{$\begin{array}{l}\text { What protocols } \\
\text { do you follow? }\end{array}$} & $\begin{array}{l}\text { Isolation } \\
\text { Retentive }\end{array}$ & $\begin{array}{c}36 \\
4.67\end{array}$ & $\begin{array}{c}1.33 \\
2\end{array}$ & $\begin{array}{c}37.33 \\
6.67\end{array}$ & & \\
\hline & $\begin{array}{l}\text { properties } \\
\text { Suitable luting } \\
\text { cement }\end{array}$ & 8 & 4.67 & 12.67 & 36.588 & $0.001^{*}$ \\
\hline & $\begin{array}{l}\text { Proper try in } \\
\text { All of the above }\end{array}$ & $\begin{array}{c}6.67 \\
14.67\end{array}$ & $\begin{array}{c}2.67 \\
19.33\end{array}$ & $\begin{array}{c}9.34 \\
34\end{array}$ & & \\
\hline \multirow{2}{*}{$\begin{array}{l}\text { What are the } \\
\text { isolation } \\
\text { methods do } \\
\text { you follow? }\end{array}$} & $\begin{array}{l}\text { Cotton rolls } \\
\text { Rubber dam }\end{array}$ & $\begin{array}{c}56 \\
4\end{array}$ & $\begin{array}{c}18 \\
2\end{array}$ & $\begin{array}{c}74 \\
6\end{array}$ & 7.465 & $0.024^{*}$ \\
\hline & $\begin{array}{l}\text { Air way } \\
\text { syringe }\end{array}$ & 10 & 10 & 20 & & \\
\hline \multirow{3}{*}{$\begin{array}{l}\text { What do you } \\
\text { think is the reason } \\
\text { for failure of } \\
\text { cementation } \\
\text { of FPD? }\end{array}$} & $\begin{array}{l}\text { Voids present } \\
\text { in the }\end{array}$ & & & & & 0.701 \\
\hline & $\begin{array}{l}\text { restoration- } \\
\text { tooth interface } \\
\text { Undercuts }\end{array}$ & $\begin{array}{l}6.67 \\
8.67\end{array}$ & $\begin{array}{l}4 \\
10\end{array}$ & $\begin{array}{l}10.67 \\
18.67\end{array}$ & 11.30 & \\
\hline & $\begin{array}{l}\text { Irregularities } \\
\text { between } \\
2 \text { materials }\end{array}$ & 5.33 & 2.67 & 8 & & \\
\hline \multirow{3}{*}{$\begin{array}{l}\text { Which step is } \\
\text { crucial for } \\
\text { prevention } \\
\text { of failure? }\end{array}$} & $\begin{array}{l}\text { Inadequate isolation } \\
\text { Proper isolation }\end{array}$ & $\begin{array}{c}49.33 \\
42\end{array}$ & $\begin{array}{c}13.33 \\
16\end{array}$ & $\begin{array}{c}62.66 \\
58\end{array}$ & 4.848 & 0.183 \\
\hline & $\begin{array}{c}\text { Retentive } \\
\text { factor }\end{array}$ & 14 & 3.33 & 17.33 & & \\
\hline & $\begin{array}{l}\text { Suitable } \\
\text { luting } \\
\text { cement }\end{array}$ & 4.67 & 4 & 8.67 & & \\
\hline \multirow{5}{*}{$\begin{array}{l}\text { What do you } \\
\text { think is the } \\
\text { common reason } \\
\text { for replacement } \\
\text { of FPD? }\end{array}$} & $\begin{array}{l}\text { Proper } \\
\text { try in }\end{array}$ & 19.33 & 6.67 & 26 & & \\
\hline & $\begin{array}{l}\text { Periodontal } \\
\text { disease }\end{array}$ & 10 & 8 & 18 & & \\
\hline & $\begin{array}{l}\text { Secondary } \\
\text { caries }\end{array}$ & 10 & 5.33 & 15.33 & 6.473 & 0.91 \\
\hline & $\begin{array}{l}\text { Fracture } \\
\text { of crown }\end{array}$ & 40 & 10.67 & 50.67 & & \\
\hline & Lack of retention & 10 & 6 & 16 & & \\
\hline
\end{tabular}




\begin{tabular}{|c|c|c|c|c|c|c|}
\hline \multirow{8}{*}{$\begin{array}{l}\text { How long do you } \\
\text { think the lifespan } \\
\text { of FPD after } \\
\text { cementation is? } \\
\text { What are the } \\
\text { difficulties you } \\
\text { used to face } \\
\text { after cementation? }\end{array}$} & Greater than 5 years & 41.33 & 28.67 & 70 & 7.539 & $0.006^{*}$ \\
\hline & $\begin{array}{c}\text { Lesser than } \\
5 \text { years }\end{array}$ & 34.67 & 5.33 & 30 & & \\
\hline & Excess cement & 41.33 & 16 & 57.33 & & \\
\hline & & & & & 0,905 & 0.824 \\
\hline & Deficient cement & 13.33 & 6.67 & 20 & & \\
\hline & Debonding & 6 & 2 & 8 & & \\
\hline & Unaesthetic & 9.33 & 5.33 & 14.66 & & \\
\hline & Lack of retention & 22 & 14 & 36 & & \\
\hline \multirow{4}{*}{$\begin{array}{l}\text { What are the } \\
\text { conditions you } \\
\text { recommend for } \\
\text { new prosthesis? }\end{array}$} & Deficient crown & 19.33 & 4 & 23 & 5.918 & 0.116 \\
\hline & Discomfort & 8.67 & 5.33 & 14 & & \\
\hline & unaesthetic & 20 & 6.67 & 26.67 & & \\
\hline & Better isolation & 26 & 3.33 & 29.33 & & \\
\hline \multirow{4}{*}{$\begin{array}{l}\text { What are the } \\
\text { steps you follow } \\
\text { during re-cementation } \\
\text { of prosthesis? }\end{array}$} & $\begin{array}{c}\text { Selection of } \\
\text { suitable }\end{array}$ & 10 & 4 & 21 & 20.015 & $0.001^{*}$ \\
\hline & cement & 13.33 & 2.67 & 16 & & \\
\hline & Uniform sealing & & & & & \\
\hline & All of the above & 20.67 & 20 & 40.67 & & \\
\hline
\end{tabular}

In relation to isolation methods followed during cementation of prosthesis, it was seen that both the undergraduates and postgraduates equally selected cotton rolls for isolation during cementation of FPD. It was in line with the study by Raigrodski et al (Raigrodski et al., 2012), where he stated that proper isolation using cotton rolls, suction tip and air way syringe during cementation of Fixed dental prosthesis will lead to increased longevity of the fixed dental prosthesis when compared to those prosthesis which was not cemented with proper isolation protocols. But this was contradictory to the study by Mitchell et al (Mitchell et al., 2009) where undergraduates were not aware of isolation as an important factor in determining the longevity of a fixed dental prosthesis. The probable reason for this could be differing sample size, less knowledge regarding protocols to be followed/ So these students have to be educated regarding the isolation protocols.

In relation to the replacement of fixed partial dentures, both undergraduates and postgraduates were equally aware about the reasons for replacement of FPD like periodontal disease, secondary caries, fracture of crown and lack of retention. Secondary caries usually occur when there is deficiency of luting cement during cementation of the prosthesis which results in marginal leakage, predisposing to secondary caries. This was stated in the study by (Song et al., 2013). Also, fractures and dislodged crowns are common when they are not properly cemented which causes premature contacts resulting in fractures and dislodgement. So it is important to follow proper cementation protocols while cementation and students should be aware of this in order to achieve prosthodontic success at the final.

In relation to the failure of Fixed partial dentures, both undergraduates and postgraduates were aware of the reasons for failure of FPD, like inadequate isolation, voids between restoration-teeth interface, undercuts. This was in line with the study by Scurria et al (Scurria, Bader and Shugars, 1998), where he stated that inadequate isolation leads to contamination of the prosthesis with saliva during cementation which results in weak bonding between the tooth and the prosthesis. Also, deficient cement and voids between restoration-tooth interfaces leads to poor bonding of the prosthesis with the tooth which reduces the lifespan of the prosthesis.In relation to the steps followed during recementation of fixed dental prosthesis, post graduates were more aware about the steps when compared to undergraduates. The reason for this may be postgraduates are the ones who will experience recementation of prosthesis when compared to undergraduates. This was in line with the study by Miettinen et al (Miettinen and Millar, 2013) It is important to follow better isolation techniques, proper selection of luting cement and uniform sealing in order to achieve successful treatment outcome. The limitations of the study include small sample size, single-centered study and examiner's subjectivity. The future scope of study is to extensive research and to educate dental students regarding the cementation protocols for fixed partial dentures which would result in successful treatment outcome and increased longevity of the fixed dental prosthesis. 


\section{CONCLUSION}

Within the limits of this study it is seen that both undergraduate and postgraduate dental students have fairly good knowledge about the cementation protocols for FPD. Postgraduates were more aware about all the cementation protocols as well as recementation of FPD. Undergraduates and postgraduates were equally aware about the reason for failure of FPD and replacement of FPD. Multiple educational webinars, conferences, scientific and panel discussions can be conducted to improve the knowledge of the students.Through increased awareness of dental students' expectations and experiences, restorations can be planned, made and placed in harmony with the hard and soft oral tissues, and in harmony with the patient's expectation as well.

\section{ACKNOWLEDGEMENTS}

I wish to express my deep sense of gratitude and professional thanks to Department of Prosthodontics, Saveetha Dental College and my college management for their keen interest, inspiring guidance, constant encouragement with my work during all stages to complete this study.

Author's Contribution: First author Vaishali.S performed data collection, analysis and interpretation and wrote the manuscript. Second author Subhabrata Maiti contributed to conception, study design, analysis, interpretation and third author Jessy P critically revised the manuscript. All the authors have discussed the results and contributed to the final manuscript.

\section{Conflict of Interest: Nil}

\section{REFERENCES}

Anbu, R. T. et al. (2019) 'Comparison of the Efficacy of Three Different Bone Regeneration Materials: An Animal Study', European journal of dentistry, 13(1), pp. 22-28.

Ariga, P. et al. (2018) 'Determination of Correlation of Width of Maxillary Anterior Teeth using Extraoral and Intraoral Factors in Indian Population: A Systematic Review', World Journal of Dentistry, 9(1), pp. 68-75.

Ashok, V. and Ganapathy, D. (2019) 'A geometrical method to classify face forms', Journal of oral biology and craniofacial research, 9(3), pp. 232-235.

Chen, M.-H. et al. (2006) 'Low shrinkage light curable nanocomposite for dental restorative material', Dental materials: official publication of the Academy of Dental Materials, 22(2), pp. 138-145.

Diaz-Arnold, A. M., Vargas, M. A. and Haselton, D. R. (1999) 'Current status of luting agents for fixed prosthodontics', The Journal of prosthetic dentistry, 81(2), pp. 135-141.

Duraisamy, R. et al. (2019) 'Compatibility of Nonoriginal Abutments With Implants: Evaluation of Microgap at the Implant-Abutment Interface, With Original and Nonoriginal Abutments', Implant dentistry, 28(3), pp.
289-295.

Evaluation of Corrosive Behavior of Four Nickelchromium Alloys in Artificial Saliva by Cyclic Polarization Test:An in vitro Study' (2017) World Journal of Dentistry, 8(6), pp. 477-482.

Fiske, J. et al. (1998) 'The emotional effects of tooth loss in edentulous people', British dental journal, 184(2), pp. 90-3; discussion 79.

Ganapathy, D. M., Kannan, A. and Venugopalan, S. (2017) 'Effect of Coated Surfaces influencing Screw Loosening in Implants: A Systematic Review and Meta-analysis', World Journal of Dentistry, 8(6), pp. 496-502.

Goodacre, C. J. et al. (2003) 'Clinical complications in fixed prosthodontics', The Journal of prosthetic dentistry, 90(1), pp. 31-41.

Gupta, P., Ariga, P. and Deogade, S. C. (2018) 'Effect of Monopoly-coating Agent on the Surface Roughness of a Tissue Conditioner Subjected to Cleansing and Disinfection: A Contact Profilometric Study', Contemporary clinical dentistry, 9(Suppl 1), pp. S122S126.

Hill, E. E. (2007) 'Dental cements for definitive luting: a review and practical clinical considerations', Dental clinics of North America, 51(3), pp. 643-58, vi.

Hill, E. E. and Rubel, B. (2009) 'Vital tooth cleaning for cementation of indirect restorations: a review', General dentistry, 57(4), pp. 392-5; quiz 396-7.

Jain, A. R. (2017a) 'Clinical and Functional Outcomes of Implant Prostheses in Fibula Free Flaps', World Journal of Dentistry, 8(3), pp. 171-176.

Jain, A. R. (2017b) 'Prevalence of Partial Edentulousness and Treatment needs in Rural Population of South India', World Journal of Dentistry, 8(3), pp. 213-217.

Kannan, A. et al. (2018) 'A knowledge, attitude, and practice survey on" the methodology followed in the fabrication of fixed partial denture amongst private practitioners", Drug Invention Today, 10(8). Available at: https://bit.ly/2XnCDoy

Keerthna, M., Dhanraj, M. and Jain, A. R. (2018) 'Knowledge on impression techniques and materials used in fixed partial dentures-A survey among dental practitioners in Chennai', Drug Invention Today. researchgate.net. Available at: https://bit.ly/33nXYSH Loera, J. M. G. (no date) 'Patient satisfaction and oral health-related quality of life outcomes in edentulous patients being treated with complete dentures by dental students at the University of Iowa College of Dentistry and Dental Clinics'. doi: 10.17077/etd.qa0x4x7y.

Macorra, J. de la, de la Macorra, J. and Pradies, G. (2002) 'Conventional and adhesive luting cements', Clinical Oral Investigations, pp. 198-204. doi: 10.1007/ s00784-002-0184-1.

Miettinen, M. and Millar, B. J. (2013) 'A review of the success and failure characteristics of resin-bonded bridges', British dental journal, 215(2), p. E3.

Mitchell, S. T. et al. (2009) 'A preliminary survey of 
impression trays used in the fabrication of fixed indirect restorations', Journal of prosthodontics: official journal of the American College of Prosthodontists, 18(7), pp. 582-588.

Prath, A. A., Ashwatha Prath, A. and Jain, A. R. (2017) 'Knowledge, attitude and practice on laminate veneer preparations among dental practitioners', Research Journal of Pharmacy and Technology, p. 1687. doi: 10.5958/0974-360x.2017.00298.0.

Raigrodski, A. J. et al. (2012) 'Survival and complications of zirconia-based fixed dental prostheses: a systematic review', The Journal of prosthetic dentistry, 107(3), pp. 170-177.

Ranganathan, H., Ganapathy, D. M. and Jain, A. R. (2017) 'Cervical and Incisal Marginal Discrepancy in Ceramic Laminate Veneering Materials: A SEM Analysis', Contemporary clinical dentistry, 8(2), pp. 272-278.

Rosenstiel, S. F., Land, M. F. and Crispin, B. J. (1998) 'Dental luting agents: A review of the current literature', The Journal of prosthetic dentistry, 80(3), pp. 280301.

Rosenstiel, S. F. and Rashid, R. G. (2003) 'Postcementation hypersensitivity: scientific data versus dentists' perceptions', Journal of prosthodontics: official journal of the American College of Prosthodontists, 12(2), pp. 73-81.

Rosenstiel, S. and Land, M. F. (2001) 'FujimotoJ: Contemporary Fixed Prosthodontics. 3” ed', St. Louis, Missouri Mosby Inc.

Scurria, M. S., Bader, J. D. and Shugars, D. A. (1998) 'Meta-analysis of fixed partial denture survival: prostheses and abutments', The Journal of prosthetic dentistry, 79(4), pp. 459-464.

Song, T.-J. et al. (2013) 'Marginal fit of anterior 3-unit fixed partial zirconia restorations using different CAD/ CAM systems', The journal of advanced prosthodontics, 5(3), pp. 219-225.

Tan, K. et al. (2004) 'A systematic review of the survival and complication rates of fixed partial dentures (FPDs) after an observation period of at least 5 years', Clinical oral implants research, 15(6), pp. 654-666.

Varghese, S. S., Ramesh, A. and Veeraiyan, D. N. (2019) 'Blended Module-Based Teaching in Biostatistics and Research Methodology: A Retrospective Study with Postgraduate Dental Students', Journal of dental education, 83(4), pp. 445-450. 